\title{
Clinical Results Associated with Changes of Posterior Tibial Slope in Total Knee Arthroplasty
}

\author{
Seung Suk Seo, MD, $\mathrm{PhD}^{1}$, Chang Wan Kim, MD, $\mathrm{PhD}^{2}$, Jung Han Kim, $\mathrm{MD}^{2}$, and Young Kyoung Min, $\mathrm{MD}^{2}$ \\ ${ }^{1}$ Department of Orthopaedic Surgery, Bumin Hospital, Busan; ${ }^{2}$ Department of Orthopedic Surgery, Inje University Busan Paik Hospital, Inje University College of \\ Medicine, Busan, Korea
}

\begin{abstract}
Purpose: The purpose of this retrospective study is to investigate the effect of posterior tibial slope (PTS) on clinical results in total knee replacement arthroplasty (TKA).

Materials and Methods: We analyzed 801 knees in 768 patients who underwent TKA using a cruciate-retaining prosthesis for osteoarthritis from July 2003 to July 2009. PTS was measured on simple X-ray films and patients were divided into 5 groups, according to the change in PTS that was calculated by subtracting the preoperative from the postoperative PTS: group $1,>3^{\circ}$; group $2,3^{\circ}$ to $1^{\circ}$; group $3,1^{\circ}$ to $-1^{\circ}$; group $4,-1^{\circ}$ to $-3^{\circ}$; and group $5,<-3^{\circ}$. We analyzed the correlations between the change in PTS and clinical results, such as Knee Society knee score, Knee Society functional score, Feller patella score, Kujala score, visual analog scale score, range of motion, and complications.

Results: There was no statistically significant intergroup difference; however, Feller patella score and Kujala score were significantly different in groups 2 and 3. There were no complications, such as progressive loosening of implants, fractures of polyethylene inserts and wears.

Conclusions: Clinically meaningful improvement was observed in all patients after TKA. Groups 2 and $3\left(3^{\circ}\right.$ to $\left.-1^{\circ}\right)$ showed significant improvement compared to the other groups.
\end{abstract}

Keywords: Total knee replacement, Arthroplasty, Knee, Posterior tibial slope

\section{Introduction}

Studies have suggested that posterior tibial slope (PTS) is associated with biomechanics of the knee joint and posterior cruciate ligament (PCL) tension and stability, and facilitates femoral rollback. Thus, it has a profound influence on the clinical outcomes of total knee arthroplasty (TKA) ${ }^{1-3}$. Several biomechanical studies have shown that PTS is positively

Received July 16, 2012; Revised (1st) August 17, 2012;

(2nd) September 4, 2012; (3rd) October 9, 2012;

(4th) October 11, 2012; Accepted October 15, 2012

Correspondence to: Chang Wan Kim, MD, PhD

Department of Orthopedic Surgery, Inje University Busan Paik Hospital, Inje University College of Medicine, 75 Bokji-ro, Busanjin-gu, Busan 614-735, Korea

Tel: +82-51-890-6257, Fax: +82-51-892-6619

E-mail: doctor-bluesea@hanmail.net

This is an Open Access article distributed under the terms of the Creative Commons Attribution Non-Commercial License (http://creativecommons.org/licenses/by-nc/3.0/) which permits unrestricted non-commercial use, distribution, and reproduction in any medium, provided the original work is properly cited. correlated with the range of flexion and inhibits excessive tension in the PCL during knee flexion, resulting in fewer instances of tibial component loosening ${ }^{4}$. However, excessive PTS can lead to anterior dislocation of the tibia and biomechanical changes of the knee, compromising the longevity of $\mathrm{TKA}^{5}$. On the other hand, the type of knee prosthesis (PCL-retaining vs. PCL-sacrificing) is an important factor that should be considered in evaluating the relationship between PTS and TKA outcomes. A majority of studies have reported that the influence of PTS on the range of motion (ROM) was notable in PCL-retaining TKA, whereas insignificant in PCL-sacrificing TKA ${ }^{6,7)}$.

The normal PTS was reported as $7^{\circ}$ by Hofmann et al. ${ }^{8)}, 8^{\circ}-10^{\circ}$ by Laskin and Reiger ${ }^{9}$, and $14.8^{\circ}$ by Chiu et al. ${ }^{10)}$. However, there is no consensus on the proper PTS for normal biomechanics of the knee joint in the absence of clinical studies.

Patellar fracture, wear or loosening, and anterior knee pain develop in approximately $50 \%$ of TKA patients ${ }^{11,12}$. These complications are associated with patellofemoral contact forces that are affected by the device design ${ }^{12)}$, patellar thickness ${ }^{13)}$, and femoral rollback in flexion. A relationship between the complications and PTS has never been investigated in clinical 
studies.

The purpose of this study is to assess the influence of intraoperative changes in PTS on clinical results under the hypotheses that 1) compared to excessive postoperative PTS, insufficient PTS after PCL-retaining TKA relatively increases anterior dislocation of the femur, which results in a higher femorotibial contact pressure and development of patellofemoral pain, and 2) PTS is positively correlated with stress on the posterior compartment of the tibia in flexion, which results in component loosening. In the absence of established intraoperative measurement methods, PTS measured from the preoperative and postoperative radiographs were used to assess the relationship between PTS change and clinical outcome and ROM.

\section{Materials and Methods}

\section{Patients}

A total of 1,028 TKAs were performed at our institution between July 2003 and July 2009. Of those, 801 cases with a minimum follow-up of 12 months were enrolled in this retrospective study. The exclusion criteria were $<90^{\circ}$ preoperative ROM, rheumatoid arthritis, traumatic or infectious arthritis, patellar resurfacing, and $\geq$ Outerbridge grade III lesion in more than $50 \%$ of the patellofemoral joint. The mean age of the enrollees was $68.4 \pm 8.1$. The surgery was performed on the right knee in 436 cases and on the left knee in 465 cases. There were 134 males and 677 females. Surgery was performed using the E-motion (Aesculap, B-Braun, Tuttlingen, Germany) PCLretaining prosthesis in all cases. The mean follow-up period was $51.2 \pm 20.2$ months.

\section{Operative Technique}

All the operations were performed by the same surgeon using a medial parapatellar approach. Proximal tibial osteotomy was performed with care to maintain the original slope of the articular surface by taking $3^{\circ}$ of posterior slope of the tibial implant into consideration. The tibial cut was followed by distal femoral osteotomy. Rotation of the femoral component was determined as $3^{\circ}-5^{\circ}$ of external rotation with respect to the posterior condylar axis based on the preoperative computed tomography (CT) scan. Taking care to avoid more than one size smaller or larger prosthesis, a femoral component that was identical as much as possible to the anteroposterior diameter of the femoral condyle was chosen using a posterior reference method. Femoral osteotomy was carried out when femoral component size was determined. The PCL was retained in TKA. If severe flexion contracture and soft tissue contracture were present, posterior osteophyte removal and partial PCL release were done to achieve flexion-extension gap balance. Patella was not resurfaced in all cases. Electrocautery and sensitization were performed for the parapatellar soft tissue structures. Normal patellar tracking was confirmed using the no thumb technique ${ }^{14)}$.

\section{Assessment and Analysis}

The mean values of PTS measured by two observers using a picture archiving and communicating system (Maroview 5.4, Marotech, Seoul, Korea) were used for analysis. The anatomical axis and mechanical axis were measured on the weight-bearing radiographs preoperatively and at the last follow-up. PTS was defined as the angle between a line perpendicular to the proximal tibial anterior cortex and a line parallel to the tibial medial plateau
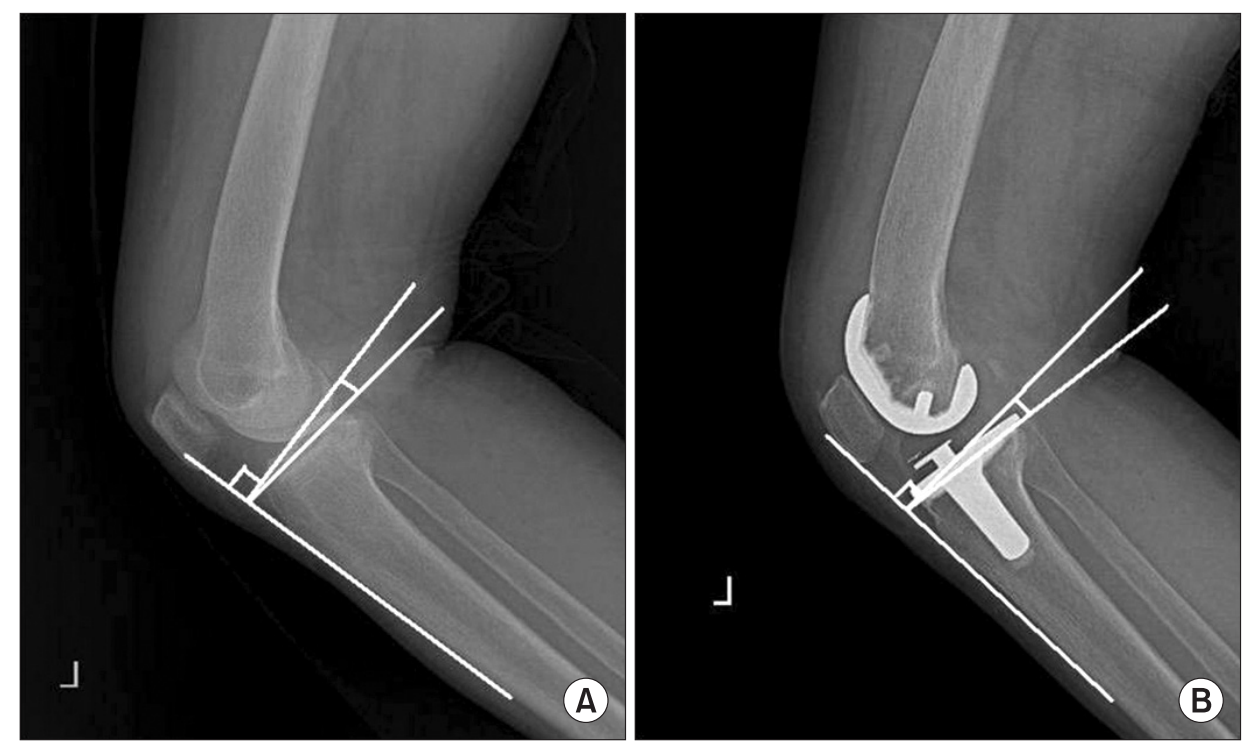

Fig. 1. (A) Preoperative tibial posterior slope line was measured by perpendicular line of proximal tibia anterior cortex and tibial medial plateau line. (B) Postoperative tibial posterior slope line was measured by perpendicular line of proximal tibia anterior cortex and tibial medial plateau line. 
on the $30^{\circ}$ flexion lateral view (Fig. 1). Patients were divided into 5 groups, according to the change in PTS that was calculated by subtracting the preoperative value from the postoperative value. If the postoperative value was greater than the preoperative value, a plus sign $(+)$ was placed in front of a numeric value, whereas a minus sign (-) was used in the opposite case: group $1,>3^{\circ}(129$ patients); group $2,3^{\circ}$ to $1^{\circ}$ (113 patients); group $3,1^{\circ}$ to $-1^{\circ}$ (312 patients), group $4,-1^{\circ}$ to $-3^{\circ}$ (163 patients); and group $5,<-3^{\circ}$ (84 patients). ROM was measured preoperatively and at the last follow-up. Knee function was assessed using the visual analog scale (VAS) score, Feller patella score ${ }^{15)}$, Kujala score ${ }^{16)}$, functional score, and Knee Society knee score (KSS) ${ }^{17)}$ preoperatively and at the last follow-up. Intergroup differences in knee function score changes between the preoperative and last follow-up examinations were analyzed using the SPSS ver. 10 (SPSS Inc., Chicago, IL, USA). The ANOVA test was performed to compare the differences in parameters among the groups and Scheffe test was conducted additionally to confirm statistical significance of the differences. The pre- and postoperative parameters in each group were assessed using paired t-tests with a $95 \%$ confidence interval.

\section{Results}

There was no statistically significant intergroup difference in the parameters that can affect the postoperative ROM and knee function including the preoperative body mass index (BMI) and ROM, VAS score, functional score, KSS, Feller patella score, and Kujala score (Table 1).
The mean preoperative anatomical axis and mechanical axis of the lower limb measured by two observers was $3.6^{\circ} \pm 4.2^{\circ}$ of varus and $7.8^{\circ} \pm 5.3^{\circ}$ of varus, respectively. The interobserver reliability of the measurements assessed with intraclass correlation coefficient (ICC) proposed by Shrout and Fleiss ${ }^{18)}$ was high with an ICC of 0.813 and 0.799 , respectively. The preoperative values were not significantly different among the groups. The mean anatomical axis and mechanical axis at the last follow-up was $8.7^{\circ} \pm 3.3^{\circ}$ of valgus and $2.4^{\circ} \pm 2.2^{\circ}$ of valgus, respectively, indicating a correction of varus deformity. The ICC for interobserver reliability was 0.803 and 0.815 , respectively. There was no significant difference among the groups in the last follow-up measurements and the amount of increase $(\mathrm{p}=0.143)$. The mean preoperative PTS was $7.1^{\circ} \pm 5.4^{\circ}$ with an ICC of 0.823 and no notable difference was found among the groups ( $\mathrm{p}=0.211$ ). The mean PTS at the last follow-up was $7.2^{\circ} \pm 2.8^{\circ}$ with an ICC of 0.812 . The VAS score, functional score, and KSS were improved postoperatively in all groups and the level of improvement was not significantly different among the groups. The Feller patella score was improved postoperatively in all the groups; however, especially significant improvement was observed in group 2 (26.3, $\mathrm{p}=0.022)$ and group $3(27.8, \mathrm{p}=0.034)$. The Kujala score was increased postoperatively in all groups, and especially significantly in group $2(76.5, \mathrm{p}=0.041)$ and group 3 (77.4, $\mathrm{p}=0.029$ ) (Table 2).

The ROM was improved postoperatively in all groups, but the level of improvement was not significantly different among the groups $(\mathrm{p}=0.241)$. There were no clinically significant complications during the follow-up, such as aseptic loosening,

Table 1. Preoperative Clinical and Radiological Scores of Each Group and p-value

\begin{tabular}{|c|c|c|c|c|c|c|}
\hline & Group I $\left(>3^{\circ}\right)$ & Group II $\left(3^{\circ}\right.$ to $\left.1^{\circ}\right)$ & Group III $\left(1^{\circ}\right.$ to $\left.-1^{\circ}\right)$ & Group IV $\left(-1^{\circ}\right.$ to $\left.-3^{\circ}\right)$ & Group V $\left(<-3^{\circ}\right)$ & $\mathrm{p}$-value $\mathrm{a}^{\mathrm{a}}$ \\
\hline No. & 129 & 113 & 312 & 163 & 84 & - \\
\hline Age (yr) & $68.6 \pm 8.0$ & $68.3 \pm 7.7$ & $68.5 \pm 8.5$ & $68.3 \pm 8.2$ & $68.4 \pm 7.9$ & 0.357 \\
\hline Body mass index $\left(\mathrm{kg} / \mathrm{m}^{2}\right)$ & $24.7 \pm 1.1$ & $24.8 \pm 1.3$ & $24.6 \pm 0.9$ & $24.7 \pm 1.2$ & $24.9 \pm 1.2$ & 0.436 \\
\hline Preoperative range of motion & $114.1 \pm 5.8$ & $117.3 \pm 6.2$ & $113.9 \pm 5.4$ & $118.1 \pm 5.9$ & $114.6 \pm 5.2$ & 0.234 \\
\hline Anatomical axis $\left({ }^{\circ}\right)$ & Varus $3.6 \pm 4.1$ & Varus $3.7 \pm 3.9$ & Varus $3.4 \pm 3.5$ & Varus $3.8 \pm 4.3$ & Varus $3.6 \pm 3.8$ & 0.189 \\
\hline Mechanical axis $\left({ }^{\circ}\right)$ & Varus $7.6 \pm 5.1$ & Varus $7.7 \pm 4.9$ & Varus $7.8 \pm 4.8$ & Varus $7.9 \pm 5.2$ & Varus $7.9 \pm 4.7$ & 0.341 \\
\hline Posterior tibial slope angle $\left({ }^{\circ}\right)$ & $7.0 \pm 5.3$ & $7.2 \pm 4.9$ & $6.9 \pm 5.1$ & $7.3 \pm 4.8$ & $7.1 \pm 5.2$ & 0.245 \\
\hline Visual analog scale & $7.8 \pm 1.5$ & $8.2 \pm 1.4$ & $8.1 \pm 1.3$ & $7.4 \pm 1.6$ & $8.0 \pm 1.4$ & 0.267 \\
\hline Knee Society functional score & $53.4 \pm 14.2$ & $55.5 \pm 13.6$ & $53.1 \pm 14.7$ & $54.7 \pm 13.9$ & $53.9 \pm 13.4$ & 0.169 \\
\hline Knee Society knee score & $55.8 \pm 21.2$ & $56.2 \pm 20.4$ & $56.3 \pm 20.2$ & $55.4 \pm 20.8$ & $55.1 \pm 20.7$ & 0.214 \\
\hline Feller patella score & $18.1 \pm 7.8$ & $18.3 \pm 7.5$ & $17.8 \pm 8.2$ & $18.2 \pm 7.7$ & $18.0 \pm 7.9$ & 0.374 \\
\hline Kujala score & $51.1 \pm 6.1$ & $51.5 \pm 6.6$ & $51.4 \pm 5.8$ & $50.8 \pm 5.9$ & $51.3 \pm 6.5$ & 0.219 \\
\hline
\end{tabular}

${ }^{a} \mathrm{~A}$ p-value is results of ANOVA test. 
Table 2. Postoperative Clinical and Radiological Scores of Each Group and p-value

\begin{tabular}{|c|c|c|c|c|c|c|}
\hline & Group I $\left(>3^{\circ}\right)$ & Group II $\left(3^{\circ}\right.$ to $\left.1^{\circ}\right)$ & Group III $\left(1^{\circ}\right.$ to $\left.-1^{\circ}\right)$ & Group IV $\left(-1^{\circ}\right.$ to $\left.-3^{\circ}\right)$ & Group V $\left(<-3^{\circ}\right)$ & p-value ${ }^{a)}$ \\
\hline No. & 129 & 113 & 312 & 163 & 84 & - \\
\hline Preoperative range of motion & $130.2 \pm 3.8$ & $129.5 \pm 4.2$ & $131.9 \pm 4.9$ & $128.9 \pm 4.7$ & $130.6 \pm 4.4$ & 0.241 \\
\hline Anatomical axis $\left({ }^{\circ}\right)$ & Valgus $8.6 \pm 3.4$ & Valgus $8.8 \pm 3.6$ & Valgus $8.5 \pm 2.9$ & Valgus $8.8 \pm 3.1$ & Valgus $8.8 \pm 3.2$ & 0.231 \\
\hline Mechanical axis $\left({ }^{\circ}\right)$ & Valgus $2.4 \pm 2.1$ & Valgus $2.3 \pm 2.3$ & Valgus $2.5 \pm 2.4$ & Valgus $2.5 \pm 2.1$ & Valgus $2.3 \pm 1.9$ & 0.254 \\
\hline Posterior tibial slope angle $\left({ }^{\circ}\right)$ & $11.7 \pm 3.1$ & $9.1 \pm 2.2$ & $7.1 \pm 2.0$ & $5.2 \pm 2.3$ & $3.5 \pm 2.2$ & $<0.001$ \\
\hline Visual analog scale & $2.6 \pm 0.8$ & $3.1 \pm 0.7$ & $3.2 \pm 1.0$ & $2.8 \pm 0.6$ & $2.9 \pm 0.7$ & 0.179 \\
\hline Knee Society functional score & $82.4 \pm 7.5$ & $83.5 \pm 8.6$ & $83.1 \pm 7.7$ & $82.7 \pm 8.9$ & $83.4 \pm 7.4$ & 0.215 \\
\hline Knee Society knee score & $86.3 \pm 8.2$ & $86.2 \pm 8.4$ & $86.3 \pm 7.2$ & $85.9 \pm 7.8$ & $86.1 \pm 7.7$ & 0.304 \\
\hline Feller patella score & $22.4 \pm 3.8$ & $26.3 \pm 2.6^{\mathrm{b})}$ & $27.8 \pm 2.1^{\mathrm{b})}$ & $23.2 \pm 3.7$ & $23.7 \pm 2.9$ & 0.014 \\
\hline Kujala score & $72.2 \pm 6.9$ & $76.5 \pm 6.1^{\mathrm{b})}$ & $77.4 \pm 5.7^{\mathrm{b})}$ & $71.8 \pm 6.5$ & $71.3 \pm 6.1$ & 0.021 \\
\hline
\end{tabular}

${ }^{\text {a) }} \mathrm{A}$ p-value is results of ANOVA test. ${ }^{\text {b) }}$ Statistically significant results.

increased radiolucency, and fracture of the polyethylene insert.

\section{Discussion}

There was no statistically significant difference in the pre- and postoperative changes in the VAS score, functional score, and KSS among the 5 groups that were divided according to the changes in the pre- and postoperative PTS. We attributed this to the fact that most of the patients had degenerative arthritis and PTS is not the only factor that influences postoperative pain, ROM limitation, and knee function. However, Feller patella score and Kujala score appeared correlated with PTS as in groups 2 and 3. It is our understanding that PTS is negatively correlated with anterior dislocation of the tibia, which results in reduced patellofemoral contact surface and stress, and eventually improvement in the Feller patella score and Kujala score. However, significant improvement was not observed in group 1 with $>3^{\circ}$ increase in PTS. We thought that the poor clinical results in this group were attributable to posterior translation of the femur, relative to the tibia, resulting in excessive traction forces on the quadriceps femoris tendon or patellar tendon or impingement of the patellar tendon during joint movement. Further, contrary to our hypothesis that PTS is correlated with the incidence of tibial component loosening due to increased pressure on the posterior compartment during flexion, there was no case of loosening in this study.

PTS increase and PCL release in TKA contribute to the improvement of flexion tightness. The latter corrects anteroposterior tightness, whereas the former enhances varus and valgus, anteroposterior, and rotational laxity in knees that are too tight in flexion. Therefore, PTS increase can be more effective than
PCL release in the knees with abnormal collateral ligament tightness and flexion tightness ${ }^{19)}$. Walker and $\mathrm{Garg}^{20)}$ reported that $30^{\circ}$ increase in flexion was observed in the knees with $10^{\circ}$ PTS compared to those with $0^{\circ}$ PTS after PCL-retaining TKA. In a cadaver study by Bellemans et al. ${ }^{21}$, flexion improved by $1.7^{\circ}$ for every $1^{\circ}$ extra PTS. However, we could not find a correlation between PTS and ROM in this study.

One of the limitations of our study is that factors, such as posterior condylar offset, that can affect the postoperative ROM were not taken into consideration in patient selection. Therefore, we think that our study results should be confirmed by future clinical and biomechanical studies with prospective design and tighter control on possible confounding variables.

\section{Conclusions}

Significant clinical improvement was observed in all the knees after PCL-retaining TKA. The improvement was especially notable in groups 2 and 3 with 3 to $-1^{\circ}$ increase in PTS compared to the other groups.

\section{Conflict of Interest}

No potential conflict of interest relevant to this article was reported.

\section{Acknowledgments}

This paper has been studied by the 2010 Inje University research grant support. 


\section{References}

1. Dejour H, Bonnin M. Tibial translation after anterior cruciate ligament rupture: two radiological tests compared. J Bone Joint Surg Br. 1994;76:745-9.

2. Hernigou P, Deschamps G. Posterior slope of the tibial implant and the outcome of unicompartmental knee arthroplasty. J Bone Joint Surg Am. 2004;86:506-11.

3. Kim KC, Choi JY, Kim JS, Chung HJ, Koo BS, Won SY. Influence of the posterior slope of the tibial component on the maximal flexion after total knee arthroplasty. J Korean Knee Soc. 1998;10:13-7.

4. Catani F, Leardini A, Ensini A, Cucca G, Bragonzoni L, Toksvig-Larsen S, Giannini S. The stability of the cemented tibial component of total knee arthroplasty: posterior cruciate-retaining versus posterior-stabilized design. J Arthroplasty. 2004;19:775-82.

5. Seo JG, Moon YW, Kim JH. Influence of posterior tibial slope on stability after total knee arthroplasty. J Korean Knee Soc. 2007;19:218-24.

6. Piazza SJ, Delp SL, Stulberg SD, Stern SH. Posterior tilting of the tibial component decreases femoral rollback in posteriorsubstituting knee replacement: a computer simulation study. J Orthop Res. 1998;16:264-70.

7. Singerman R, Dean JC, Pagan HD, Goldberg VM. Decreased posterior tibial slope increases strain in the posterior cruciate ligament following total knee arthroplasty. J Arthroplasty. 1996;11:99-103.

8. Hofmann AA, Bachus KN, Wyatt RW. Effect of the tibial cut on subsidence following total knee arthroplasty. Clin Orthop Relat Res. 1991;(269):63-9.

9. Laskin RS, Rieger MA. The surgical technique for performing a total knee replacement arthroplasty. Orthop Clin North Am. 1989;20:31-48.

10. Chiu KY, Zhang SD, Zhang GH. Posterior slope of tibial plateau in Chinese. J Arthroplasty. 2000;15:224-7.

11. Petersilge WJ, Oishi CS, Kaufman KR, Irby SE, Colwell CW Jr. The effect of trochlear design on patellofemoral shear and compressive forces in total knee arthroplasty. Clin Orthop Relat Res. 1994;(309):124-30.

12. Singerman R, Berilla J, Kotzar G, Daly J, Davy DT. A sixdegree-of-freedom transducer for in vitro measurement of patellofemoral contact forces. J Biomech. 1994;27:233-8.

13. Star MJ, Kaufman KR, Irby SE, Colwell CW Jr. The effects of patellar thickness on patellofemoral forces after resurfacing. Clin Orthop Relat Res. 1996;(322):279-84.

14. Scott RD. Prosthetic replacement of the patellofemoral joint. Orthop Clin North Am. 1979;10:129-37.

15. Feller JA, Bartlett RJ, Lang DM. Patellar resurfacing versus retention in total knee arthroplasty. J Bone Joint Surg Br. 1996;78:226-8.

16. Kujala UM, Jaakkola LH, Koskinen SK, Taimela S, Hurme M, Nelimarkka O. Scoring of patellofemoral disorders. Arthroscopy. 1993;9:159-63.

17. Insall JN, Dorr LD, Scott RD, Scott WN. Rationale of the Knee Society clinical rating system. Clin Orthop Relat Res. 1989;(248):13-4.

18. Shrout PE, Fleiss JL. Intraclass correlations: uses in assessing rater reliability. Psychol Bull. 1979;86:420-8.

19. Jojima H, Whiteside LA, Ogata K. Effect of tibial slope or posterior cruciate ligament release on knee kinematics. Clin Orthop Relat Res. 2004;(426):194-8.

20. Walker PS, Garg A. Range of motion in total knee arthroplasty: a computer analysis. Clin Orthop Relat Res. 1991; (262):227-35.

21. Bellemans J, Robijns F, Duerinckx J, Banks S, Vandenneucker $H$. The influence of tibial slope on maximal flexion after total knee arthroplasty. Knee Surg Sports Traumatol Arthrosc. 2005;13:193-6. 